\title{
INSTRUMENTOS PARA LA VIDA, OFRENDAS PARA LA MUERTE: UN ESTUDIO DEL AJUAR FUNERARIO WARI DE HUACA PUCLLANA
}

\author{
GLADYS Paz FLoRes \\ Proyecto de InVestigación, Conservación y Puesta en Valor Huaca Pucllana \\ pazflores.gladys@gmail.com
}

\section{RESUMEN}

En los últimos años del Proyecto de Investigación, Conservación y Puesta en Valor Huaca Pucllana (PICPVHP), dirigido por la Dra. Isabel Flores Espinoza, los contextos funerarios Wari ubicados en la cima de la Gran Pirámide se han convertido en el principal foco de estudio. En ellos, han sido encontrados una gran cantidad de elementos in situ y en buen estado de conservación, tales como estructuras, fardos funerarios y ofrendas. El presente artículo aborda el estudio de estas últimas, proponiendo una tipología al interior del ajuar funerario Wari, el cual —en base a su disposición, características y contenido-nos proporciona información sobre las personas enterradas y los participantes del ritual funerario. Esto, tomando en consideración el análisis de restos óseos, tejidos y elementos vegetales, entre otros, a cargo de los especialistas del proyecto. De este modo, podemos obtener resultados que nos ayuden con la discusión del tema y con las interpretaciones finales.

Palabras Claves: Huaca Pucllana, Costa Central, Contextos Funerarios, Wari, Ofrendas.

\section{ABSTRACT}

During the last years of Huaca Pucllana Project of Research, Conservation and Re-Valuation (PICPVHP), directed by Dr. Isabel Flores Espinoza, the Wari funerary contexts found on top of the Great Pyramid have become the main focus of study. There, several elements were found on the site in good state of preservation, such as structures, funerary bundles and offerings. The present article deals with these offerings and their study, and it suggests a typology inside the Wari funerary objects, which provide us information about the people who were buried there and the participants during the funerary ritual, according to their position, specific features and contents. All of this takes into consideration the analysis of bone remains, fabric and vegetal tissue by the Project's specialists. These analysis are done in order to obtain results that will help us with the discussion of this topic and further interpretations.

KeYwords: Huaca Pucllana, Central Coast, Funerary contexts, Wari, offerings. 


\section{GENERALIDADES}

Las ofrendas funerarias siempre han sido un objeto de estudio de gran interés por parte de los investigadores del área andina. Existen numerosos trabajos relacionados al tema desde épocas prehispánicas hasta las modernas y desde disciplinas tan variadas como la etnografía, historia y la antropología, entre otras. Esto se debe a que la muerte ha sido siempre difícil de comprender y por ello, cada sociedad ha intentado vincularla con lo sobrenatural. A lo largo de la historia de los grupos sociales desarrollados en el área andina, existen diversos patrones de enterramiento asociados a ofrendas, por ende, estos son reconocidos como una práctica social significativa y se convierten en una variable importante para entender diferencias y similitudes culturales. Los grupos humanos, en tal sentido, han ofrendado objetos, personas, animales y acciones para ciertos momentos y contextos apropiados de manera organizada y estructurada (Chacaltana y Nash 2009: 158) ${ }^{1}$. Tal es así que en una investigación durante el s. XVII, se definió que uno de los principales cultos de los antiguos peruanos era el que se rendía a los muertos, y su importancia se debió a una directa relación con la agricultura. "La misma palabra mallqui, según el Dr. Luis E. Valcárcel (1964) significa 'momia de los antepasados, árbol para replantar, árbol frutal'. Esta íntima relación se trasluce cuando los campesinos antes de comenzar a sembrar regaban sobre la tierra preparada chicha, coca e invocaban a sus difuntos, para que guardasen las chacras, para que las cosechas fueran buenas" (Huertas 1981: 61).

Además, desde la perspectiva arqueológica, las ofrendas que son analizadas dentro de un contexto también nos permiten inferir sobre la manera en que se comportaban los humanos del pasado (Chacaltana y Nash 2009: 158).

De la época del Horizonte Medio podemos decir, por ejemplo, que surgen grandes cambios sociales, económicos, políticos y jerárquicos (Isbell 1988) que no solo fueron reflejados en los patrones de asentamiento y en la obtención de recursos, sino que además la diferencia hallada en los patrones funerarios demostraría el desarrollo político y social del imperio Wari (Lumbreras 1980). Por otro lado, Shady (1988) ha relacionado este cambio sociopolítico a una serie de Estados Regionales enlazados entre sí, por medio de redes de intercambio que ejercieron control sobre sus propias áreas.

En el área de la Costa Central observamos que existe la mayor información referida a los contextos funerarios de esta época, registrados en Ancón (Segura 1997, Kaulicke 1997), Pachacamac (Kaulicke 2000), Garagay, Catalina Huanca (Cornejo 2007, Álvarez 2011), Cajamarquilla (Mogrovejo y Segura 2000), Cayan y Lauri (Villacorta y Tosso 2000) en el Valle de Chancay y Huaca Malena al sur de Lima (Pozzi y Ángeles 2005) y desde el año 2005 han sido registrados los primeros contextos funerarios de la época Wari encontrados en el sitio de Huaca Pucllana (Flores 2005, 2012, 2013) (Figura 1).

El sitio de Huaca Pucllana se encuentra ubicado en la parte baja del valle del río Rímac, a 2 km del litoral limeño, y actualmente ocupa 6 ha en el distrito de Miraflores (Figura 2). Desde 1981 hasta la fecha se realizan trabajos de excavación, conservación y puesta en valor bajo la dirección de la Dra. Isabel Flores Espinoza, los cuales han dado como resultado la exposición de una Gran Pirámide de siete plataformas y el Complejo Noreste de carácter administrativo, construidos entre los años 450 d.C.y 650 d.C. en la época 1 del Horizonte Medio. La arquitectura del lugar demuestra un gran poder político y económico alcanzado para la época. Sin embargo, después de ser abandonada, los Wari instalaron

1. Si bien esta cita está incluida en la publicación de los autores citados, el enunciado en específico corresponde al autor Lawrence Kuznar (2001) en An Introduction to Andean Religious Ethnoarchaeology: Preliminary Results and Future Directions, que forma parte de Etnoarchaeology of Andean South America, editado por Lawrence Kuznar, pp. 38-66. Ethnoarchaeological Series 4, Ann Arbor. 
un cementerio para sus personajes de élite en la cima de la Gran Pirámide, modificando la arquitectura con el fin de instalar sus tumbas, las cuales contienen fardos funerarios y ofrendas.

Hasta el año 2013, han sido registradas más de 63 tumbas en el cementerio de Huaca Pucllana; de ellas, la mayoría se encuentra alterada producto de un probable saqueo prehispánico. Este cementerio fue construido entre los años 850-870 d.C. (en la época 2B-3 del Horizonte Medio, de acuerdo a los fechados radiocarbónicos), período que corresponde a la consolidación del Imperio Wari (Flores et al. 2012, Flores 2013) (Figura 3).

Durante la temporada de excavación del año 2009 del Proyecto de Investigación, Conservación y Puesta en Valor Huaca Pucllana, fue intervenida un área de $100 \mathrm{~m}^{2}$, ubicada en la cima de la Gran Pirámide, al noreste de la Plataforma 6. Junto a un equipo de especialistas, fueron halladas dos tumbas: CF A20-04(09) y CF A20-15(09). Ambas tienen la particularidad de tener intactas parte de la ofrenda principal y las secundarias. Este hallazgo, junto a otros de características similares registrados anteriormente, nos ha permitido delinear esta investigación sobre la tipología de ofrendas encontradas dentro de las tumbas del Cementerio Wari de Huaca Pucllana.

El análisis y apertura de dos ofrendas principales se realizaron en gabinete, posterior a la recuperación en campo. El registro escrito, gráfico y fotográfico de este trabajo nos permite presentar detalladamente las características de cada una de ellas.

\section{OFRENDAS FUNERARIAS WARI}

Tal como lo conceptualizan las investigaciones previas del sitio, una ofrenda es entendida como el elemento o conjunto de elementos dispuestos al interior de una tumba, cercanos a los individuos o fardos funerarios (en el caso Wari). Estas ofrendas "casi siempre se encuentran dispuestas en las partes delantera y laterales de los fardos funerarios, algunas veces sobre petates de junco o totora. Entre los objetos que componen la ofrenda se observan vasijas de cerámica, vasijas de mate, instrumentos de hilandería y textilería, objetos de madera, ofrendas de frutos y animales, tejidos de cestería, tejidos y adornos, entre otras ofrendas" (Flores, 2013:45).

Asimismo, se menciona que las ofrendas externas se dividen en ofrendas principales y ofrendas secundarias. Se propone que una ofrenda principal de un entierro Wari presenta características particulares. Pueden ser consideradas del tipo atado, entendido por Flores Ochoa como una ofrenda dedicatoria que contiene varios atributos envueltos en un textil (Chacaltana y Nash 2009: 159) o del tipo envoltorio, ambas mantienen su carácter único y personalizado con algunos elementos recurrentes en su interior: cestas, vasijas de cerámica o mate, bolsas tejidas con instrumentos de madera o restos orgánicos, como las que se describen a continuación.

\section{OFRENDA № 1}

\section{Procedencia}

Esta ofrenda proviene del contexto funerario denominado CF A20-04(09) ${ }^{2}$, ubicado al lado noreste de la plataforma 6. El contexto está compuesto de una estructura funeraria de tipo pozo. Para su construcción, destruyeron parte de una rampa y utilizaron uno de los muros ejes orientados de Este a Oeste, pertenecientes a la última ocupación (IV Fase Constructiva). Se trata de una tumba múltiple alterada en sus niveles superficiales. Los primeros testigos de material cultural fueron restos de

2. Véase Informe final de las actividades realizadas por el Proyecto de Investigación, Conservación y puesta en valor Huaca Pucllana 2009 presentado al Ministerio de Cultura, Lima. (Flores, 2010) 


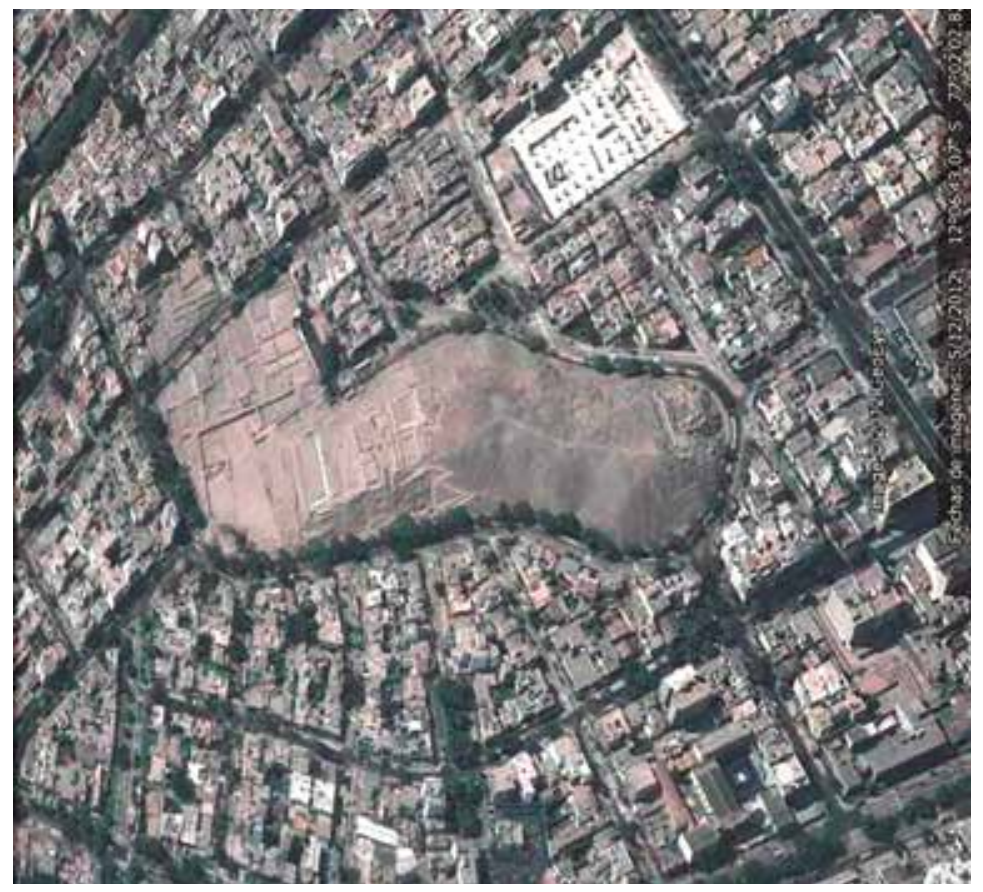

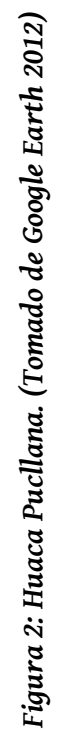
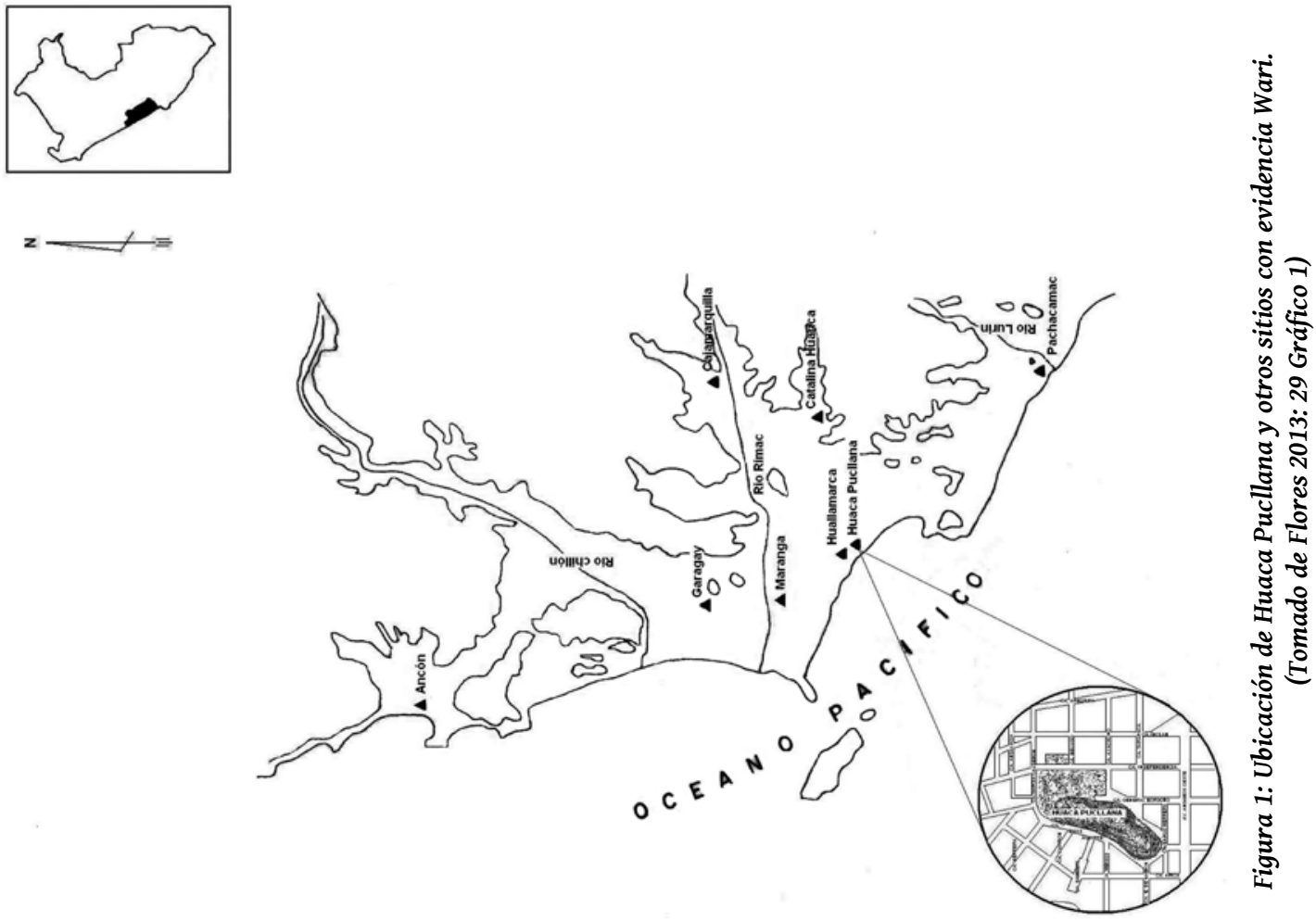

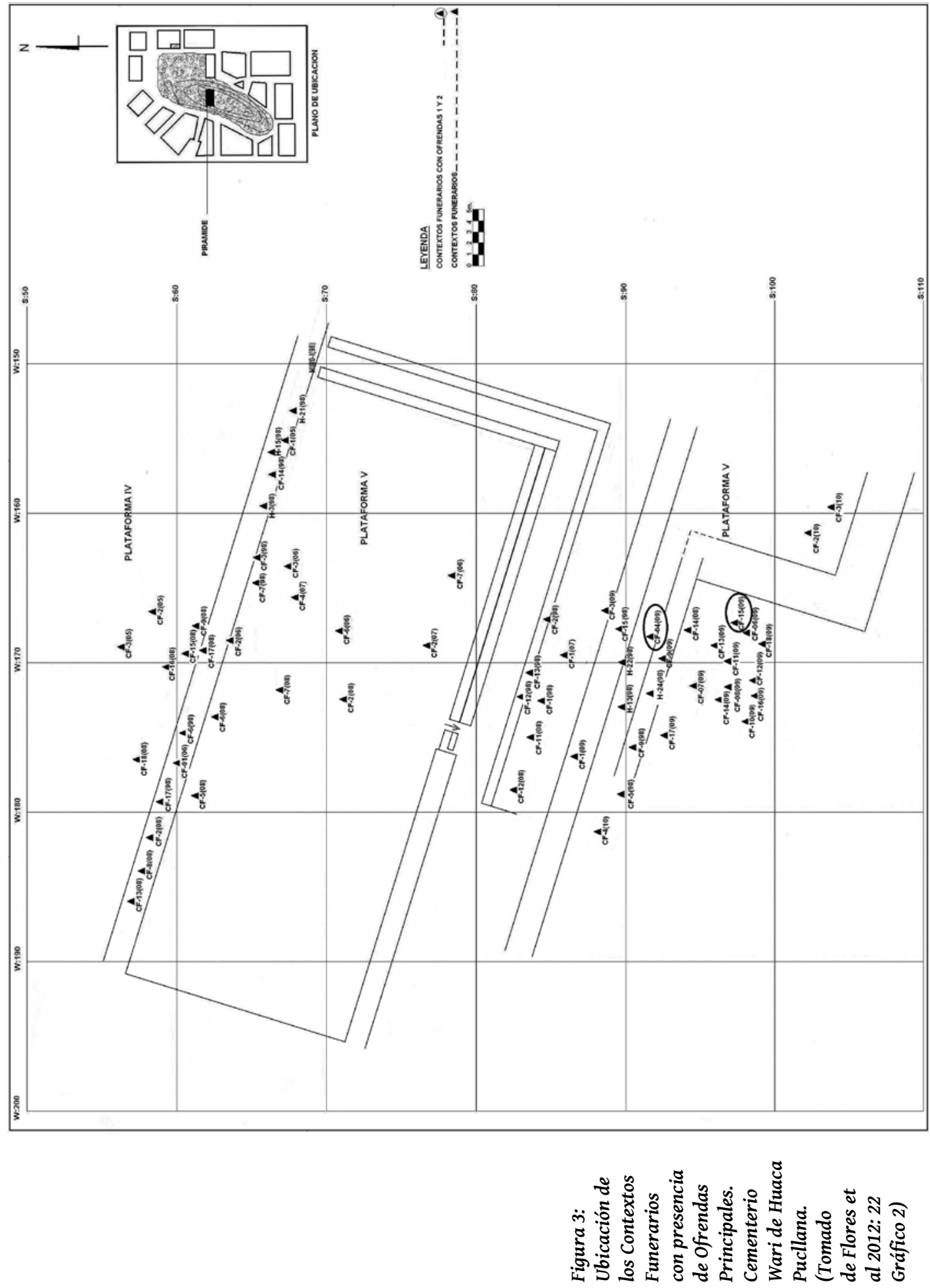
troncos dispuestos de manera desordenada que habrían conformado el techo de la estructura, instrumentos de textilería e hilandería, restos osteológicos desarticulados y elementos de los fardos como ojos de falsa cabeza, soguillas en técnica trenzada y en técnica de torsión, entre otros materiales. Por otro lado, los niveles inferiores no fueron afectados por esta remoción. En ellos se encontraron tejidos, vasijas de cerámica (botella asa-puente, cántaro), cuencos de mate, instrumentos de madera y la ofrenda principal denominada Ofrenda № 1. Asimismo, la disposición de los elementos al interior de la tumba fue remarcada con la presencia de un petate en la base. Las ofrendas asociadas, por su parte, se encontraban dispuestas hacia el lado Este, mientras que los fardos habrían estado ubicados hacia los lados Norte y Sur. Finalmente, se halló parte de un fardo perteneciente a un adulto que probablemente correspondió a uno de los acompañantes (Figura 4).

\section{DESCRIPCIÓN}

La ofrenda № 1 se caracteriza por ser del tipo “atado", de forma voluminosa y contornos ovalados, hallada en el extremo sureste al interior de la tumba junto a instrumentos de madera de tipo paleta y bolsas con tuzas de maíz al interior. Mide $23 \mathrm{~cm}$ de largo por $19 \mathrm{~cm}$ de ancho y $13 \mathrm{~cm}$ de altura. El textil que cubre el atado está confeccionado por cuatro piezas de tejido de forma rectangular, dos de color blanco y las otras dos de color marrón claro, elaboradas con fibra de algodón (Gossypium barbadense). Se disponen de forma intercalada y están unidas por medio de una costura de tipo surjete, formando un solo paño rectangular de $60 \mathrm{~cm}$ por $50 \mathrm{~cm}$. En la intersección de los cuatro paños, sobre el tejido extendido, fueron colocados un conjunto de elementos de forma ordenada y, posteriormente, fueron cubiertos con estos paños, atándolos a través de 3 nudos simples muy ajustados, realizados de derecha a izquierda.

\section{CONTENIDo}

El orden de los elementos al interior del atado se divide en dos niveles: superior e inferior (Figura 5 y 6 ).

\section{Nivel SuPERIOR}

El nivel superior se compone de una bolsa de forma rectangular de $31 \mathrm{~cm}$ de largo por $23 \mathrm{~cm}$ de ancho, elaborada en fibra de algodón de color pardo y técnica cara de urdimbre con diseños lineales a lo largo, en colores blanco, marrón y rojo. Al interior presenta 5 contenedores ${ }^{3}$ de Erythoroxylum coca, dispuestos de forma ordenada uno junto al otro, en su mayoría carbonizados debido a la degradación del tejido, lo que demuestra que el contenido fue colocado fresco en el lugar (Figura 7).

Contenedor 1. Está conformado por un paño de forma cuadrangular de $30 \mathrm{~cm}$ largo por $29 \mathrm{~cm}$ de ancho, elaborado en fibra de algodón de color blanco y técnica cara de urdimbre. Presenta decoración en la parte central del paño, consistente en seis secciones rectangulares con diseños de rombos, tres de ellos de color fucsia, dos de color amarillo ocre y la parte inferior de color azul, elaboradas en fibra de pelo de camélido teñido y técnica de brocado. Se halló atada por medio de un nudo simple, que parte de dos de sus esquinas opuestas. Contiene $2.7 \mathrm{gr}$ de hojas de coca dispuestas en la parte central, directamente sobre los diseños del tejido.

3. Término utilizado por Belmonte Eliana, Ortega Marietta, Arévalo Patricia, Cassman Vicki y Cartmell Larry en Presencia en el Ajuar Funerario de tres cementerios del periodo Tiawanaku: Az 140, Az 6 y Plm 3 2001, referido a bolsas ceremoniales precolombinas con hojas de coca como parte del ajuar funerario. 


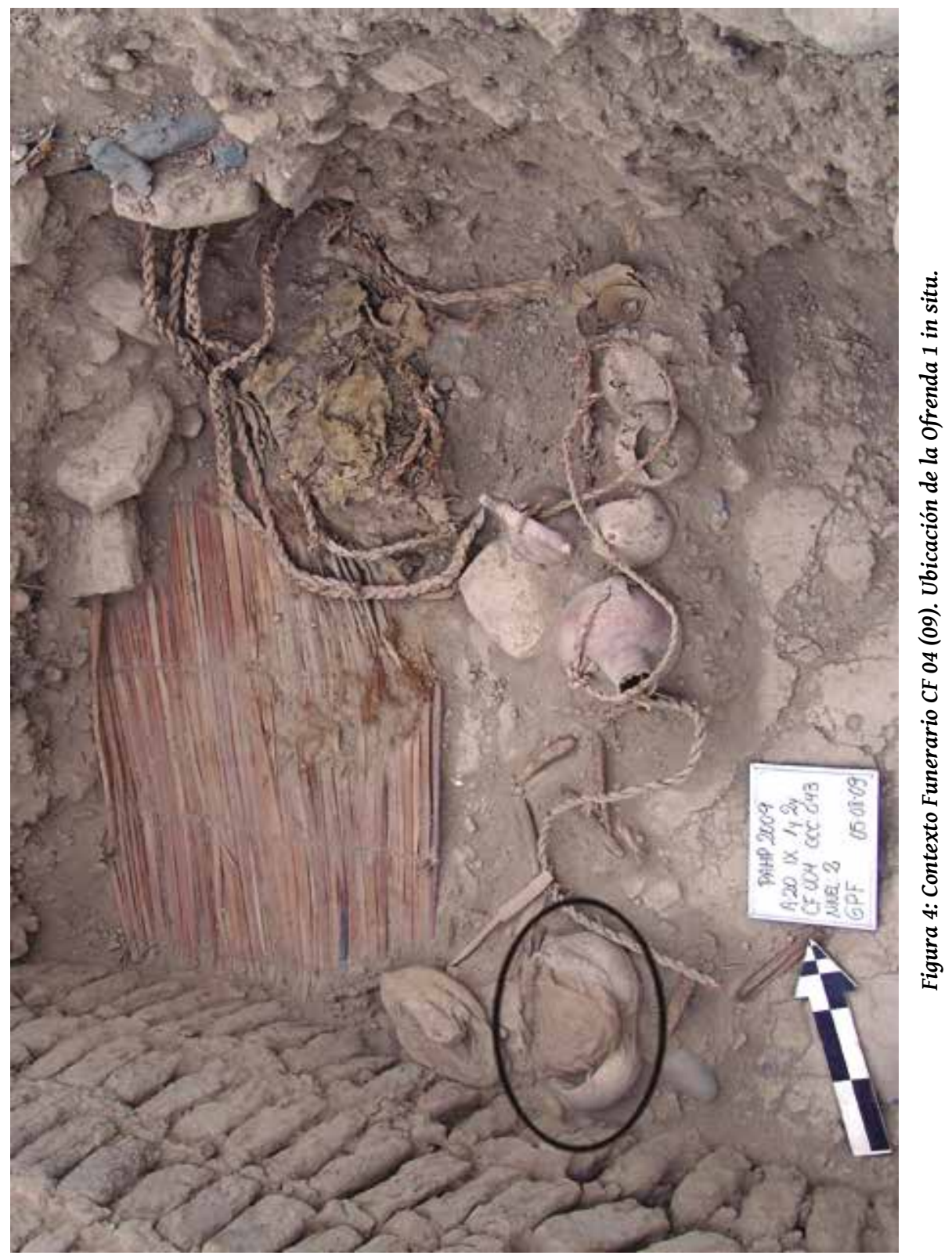




\begin{tabular}{|c|c|c|c|c|}
\hline \multirow{7}{*}{ 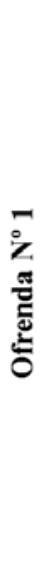 } & \multirow{5}{*}{ Nivel Superior } & \multirow{5}{*}{ Bolsa } & Contenedor 1 & $\begin{array}{l}2,7 \text { gr de Erythoroxylum } \\
\text { coca }\end{array}$ \\
\hline & & & Contenedor 2 & $\begin{array}{l}\text { 9,6 gr de Erythoroxylum } \\
\text { coca }\end{array}$ \\
\hline & & & Contenedor 3 & $\begin{array}{l}11,5 \text { gr de } \\
\text { Erythoroxylum coca }\end{array}$ \\
\hline & & & Contenedor 4 & $\begin{array}{l}24,1 \mathrm{gr} \text { de } \\
\text { Erythoroxylum coca }\end{array}$ \\
\hline & & & Contenedor 5 & 9.1 Erythoroxylum coca \\
\hline & & Cuenco a & & ra de cabuya \\
\hline & Nivel inferior & Cuenco b & Bolsa pequeña & $\begin{array}{l}\text { Restos ictiologicos } \\
\text { Sardinops sagax sagax } \\
\text { (Sardina) y Sciaena } \\
\text { deliciosa (Lorna) }\end{array}$ \\
\hline
\end{tabular}

Figura 5: Tabla 1. Contenido de Ofrenda 1.

\section{OFRENDA $N^{\circ} 1$}

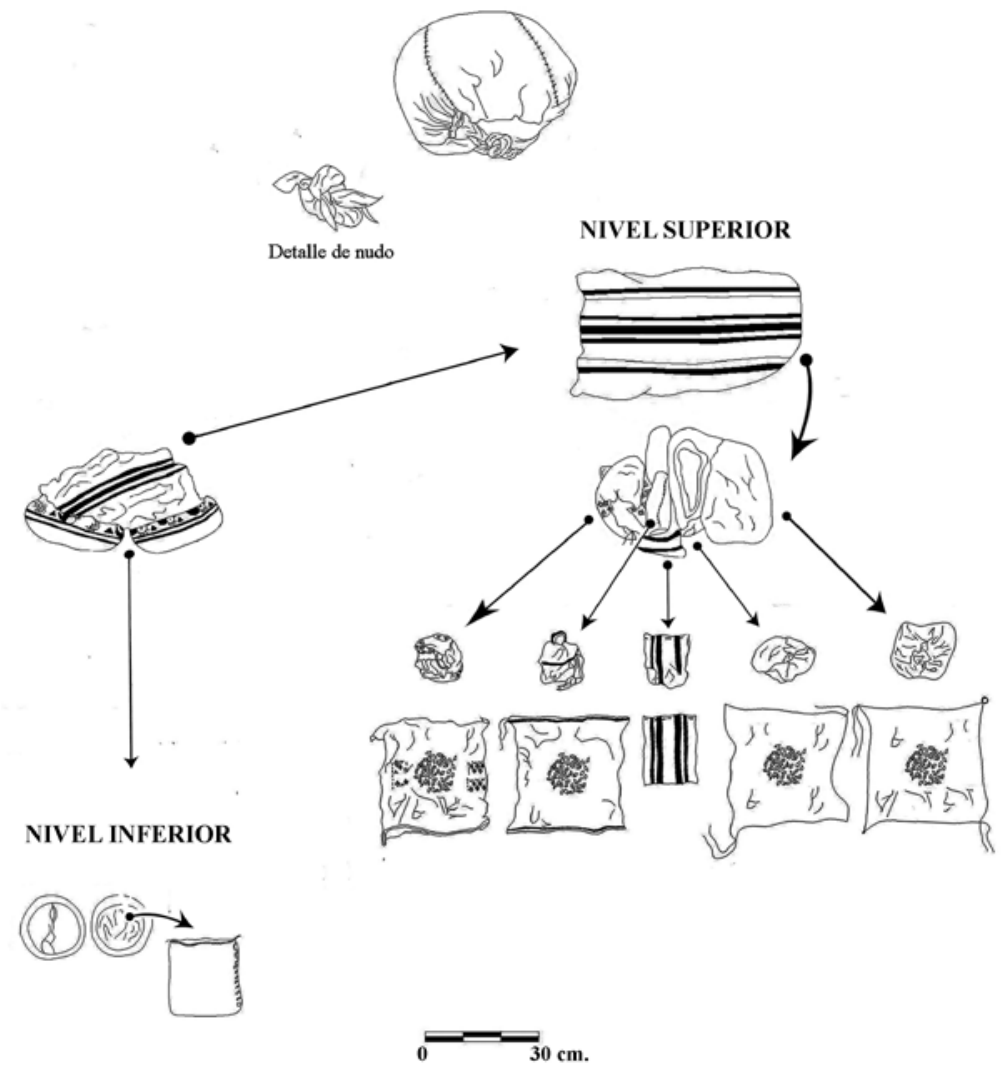

Figura 6: Dibujo reconstructivo de la Ofrenda 1 


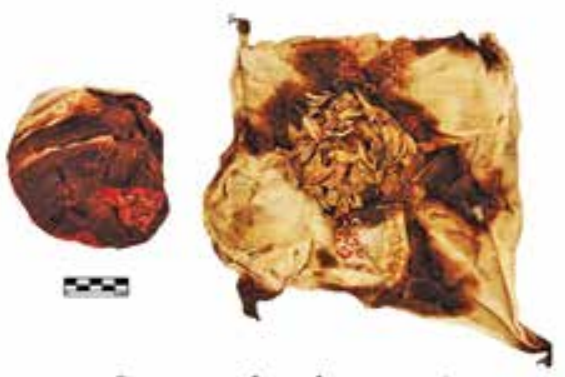

Contenedor de coca 1

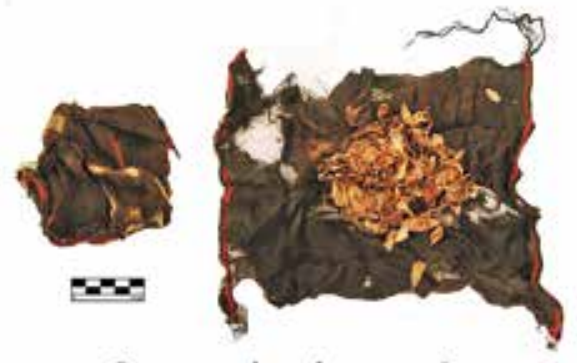

Contenedor de coca 2

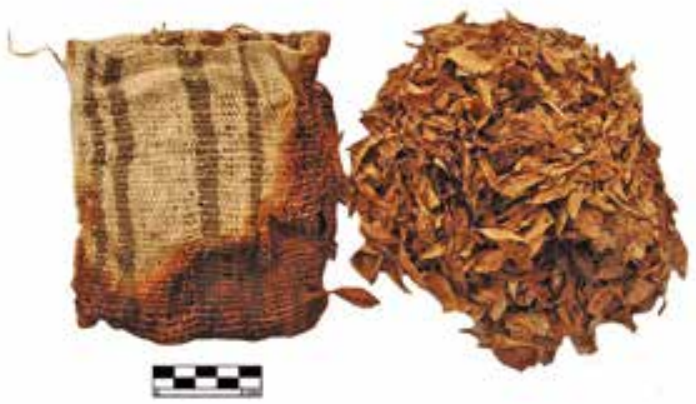

Contenedor de coca 3

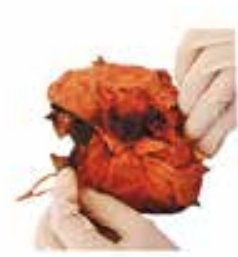

Contenedor de coca 4
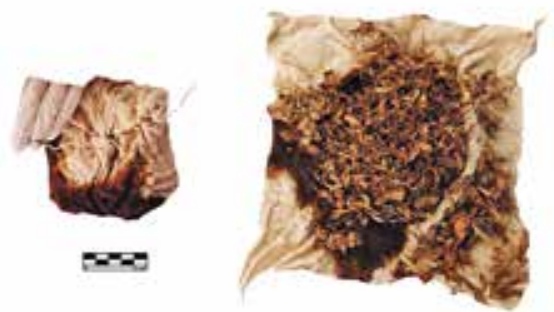

Contenedor de coca 5

Figura 7: Contenedores de coca. 
Contenedor 2. Se trata de un paño de forma cuadrangular de $23 \mathrm{~cm}$ de largo por $23 \mathrm{~cm}$ de ancho, elaborado en fibra de algodón de color marrón en técnica cara de urdimbre, con decoración listada de color rosado en los ejes de trama. Se encuentra atada en la parte central por medio de un nudo simple desde dos esquinas opuestas, formando un atado pequeño de contornos ovalados. Contiene $9.6 \mathrm{gr}$ de hojas de coca dispuestas al centro del tejido extendido.

Contenedor 3. Este elemento se diferencia de los otros contenedores: se trata de una bolsa elaborada por un paño doblado y cosido en los extremos de forma rectangular, en fibra de algodón de color beige y técnica cara de urdimbre, con decoración listada en color gris. Mide $14 \mathrm{~cm}$ de largo por $12 \mathrm{~cm}$ de ancho y fue cosida mediante la técnica de tipo hilván hacia un lado y costura de tipo surjete hacia el lado opuesto, asegurando el contenido de 11.5 gr de hojas de coca al interior.

Contenedor 4. Paño de forma cuadrangular de $27 \mathrm{~cm}$ de largo por $26 \mathrm{~cm}$ de ancho, elaborado en fibra de algodón teñida y técnica de tejido llano 1x1 de color anaranjado, con hilos que sobresalen de las cuatro esquinas. Se encuentra atado por medio de dos nudos simples y contiene 24.1 gr de hojas de coca, dispuestas en la parte media del tejido extendido.

Contenedor 5. Se trata de un tejido de forma cuadrangular de $29 \mathrm{~cm}$ de largo por $26 \mathrm{~cm}$ de ancho, elaborado en fibra de algodón de color blanco y en técnica de tejido llano 1x1. Contiene 9.1 gr de hojas de coca al interior, dispuestas en la parte central. Lleva un nudo simple, conformado por las dos esquinas opuestas del tejido, además de hilos cosidos de forma desordenada con el fin de asegurar el contenido en su interior, los cuales sobresalen de las esquinas.

\section{NiVEL INFERIOR:}

Es el nivel de elementos que se encuentran colocados sobre el tejido, compuestos de dos cuencos de mate que se disponen uno al lado del otro y presentan similares características formales, decorados con diseños elaborados con la técnica de pirograbado sobre la superficie externa.

El cuenco "a" tiene dibujado dos líneas centradas en todo el contorno de la superficie externa, sobre las que se disponen seis escenas separadas por medio de figuras triangulares. Cinco de ellas consisten en el enfrentamiento de un ave con un pez y la otra lleva los mismos personajes mirando a lados opuestos.

El pez representado se dispone de forma curva hacia el lado izquierdo. Su cuerpo está conformado por figuras geométricas: la cabeza hacia la parte inferior - donde sobresalen 3 líneas rectas- presenta similares características a iconografías encontradas anteriormente sobre soportes de mate y textil de temporadas anteriores ${ }^{4}$. Contiene un conjunto de fibras de cabuya y mide $12 \mathrm{~cm}$ de diámetro por $6 \mathrm{~cm}$ de altura.

El cuenco "b" lleva sobre su superficie diez representaciones de arácnidos, dispuestas en sentido antihorario, que otorgan un efecto de movimiento de rotación. La figura está compuesta por un círculo de $1 \mathrm{~cm}$ de diámetro de color negro junto a otro de la misma dimensión, sin relleno, con un punto en la parte central, el cual representa el ojo y 8 líneas trazadas a modo de extremidades. Cada representación de la araña está separada por medio de figuras triangulares. Al interior, lleva una bolsa de $15 \mathrm{~cm}$ de largo por $13 \mathrm{~cm}$ de ancho, elaborada en fibra de algodón de color blanco y técnica cara de urdimbre, la cual contiene restos ictiológicos de dos especies marinas: Sardinops sagax sagax (sardina) y Sciaena deliciosa (lorna), cerrada en la parte superior por medio de una costura de tipo

4. Véase Informe Final de Proyecto de Investigación, Conservación y Puesta en Valor Huaca Pucllana presentado al Ministerio de Cultura (Flores, 2010). 
surjete. Es probable que los restos ictiológicos hayan sido colocados aún frescos debido a la marca de carbonización que presenta el tejido. (Figura 8 A y 8 B).

\section{OFRENDA № 2}

\section{Procedencia}

Se halla dentro del ajuar funerario de la tumba CF A20-15(09) ${ }^{5}$, ubicada en el lado este de la plataforma 6, en la cima de la Gran Pirámide.

La estructura funeraria es de tipo pozo, de forma rectangular y orientada de Sureste a Noroeste. Mide $1.55 \mathrm{~m}$ de largo por $90 \mathrm{~cm}$ de ancho. Para la construcción de la cámara, destruyeron parte de la arquitectura de la última ocupación (IV Fase Constructiva) y utilizaron parte de los muros para construir las paredes internas de la tumba.

Se encontraron restos de algunos componentes de los fardos funerarios, como soguillas de totora en técnica trenzada, nariz de falsa cabeza representada en madera, fragmentos de tejido y restos óseos de adultos e infantes, además de un bloque de barro de $45 \mathrm{~cm}$ de largo por $20 \mathrm{~cm}$ de ancho en los niveles superiores que se hallaban alterados.

En el nivel inferior, las ofrendas quedaron en su posición original: siete vasijas de mate (cuencos, botellas), tuzas de maíz, bolsas tejidas y la ofrenda principal, denominada ofrenda № 2 , hacia la esquina noroeste. Sobre la base se observan restos de soguillas trenzadas y dispuestas en forma en espiral con restos de ceniza, las cuales habrían formado parte de la base de dos fardos de adultos (Figura 9).

\section{Descripción}

La ofrenda 2 tiene forma alargada de $33 \mathrm{~cm}$ de largo por $21 \mathrm{~cm}$ de ancho y $9.5 \mathrm{~cm}$ de altura y contiene un conjunto de elementos relacionados con la actividad textil. El envoltorio externo es un paño de forma rectangular, cuyas dimensiones son de $53 \mathrm{~cm}$ de largo por $50 \mathrm{~cm}$ de ancho. Está elaborado en fibra de algodón (Gossypium barbadense) de color blanco y confeccionado en la técnica de tejido llano 1x1. Los elementos internos fueron dispuestos en la parte central del tejido extendido, cubiertos por las esquinas y cosidos posteriormente por medio de un hilo de algodón en costura de tipo surjete e hilván. Las puntadas de las costuras son espaciadas, por lo que se infiere que fueron hechas con agujas de gran longitud.

\section{Contenido}

El orden de los elementos al interior del atado se divide en dos niveles: superior e inferior (Figura $10 \mathrm{y} 11)$.

\section{NiVEL SUPERIOR}

Está compuesto de dos elementos: un atado pequeño y una bolsa tejida de forma rectangular, la cual contiene instrumentos relacionados a la actividad textil.

El atado se compone de una pieza tejida de forma cuadrangular de $16 \mathrm{~cm}$ de largo por $14 \mathrm{~cm}$ de ancho, elaborado en fibra de algodón de color marrón, con decoración listada cerca de dos orillos opuestos de color rojo en fibra de pelo de camélido teñido, ambos en técnica cara de urdimbre. Al in-

5. Véase Informe Final de Proyecto de Investigación, Conservación y Puesta en Valor Huaca Pucllana presentado al Ministerio de Cultura (Flores, 2010). 

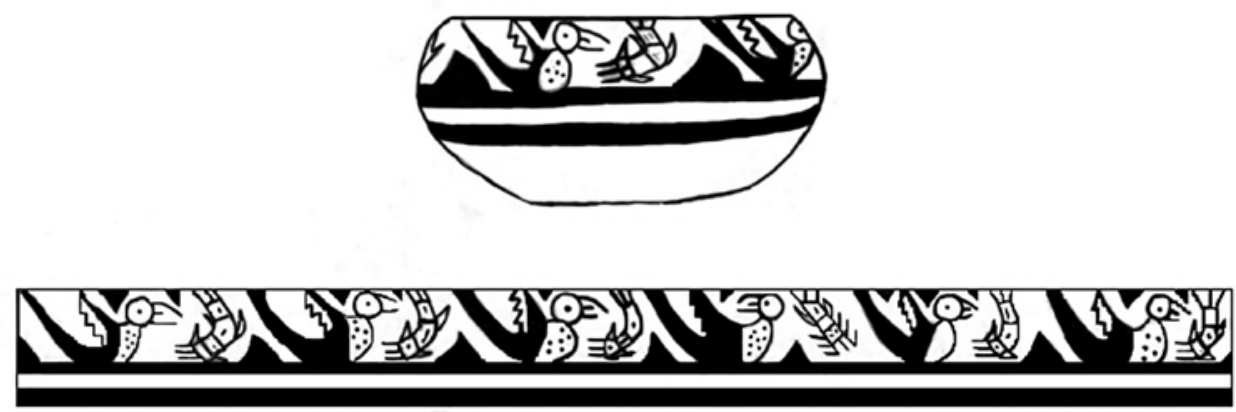

FIG. $8 \mathrm{~A}$

Figura 8 A: Cuenco de mate " $a$ ". Iconografía.
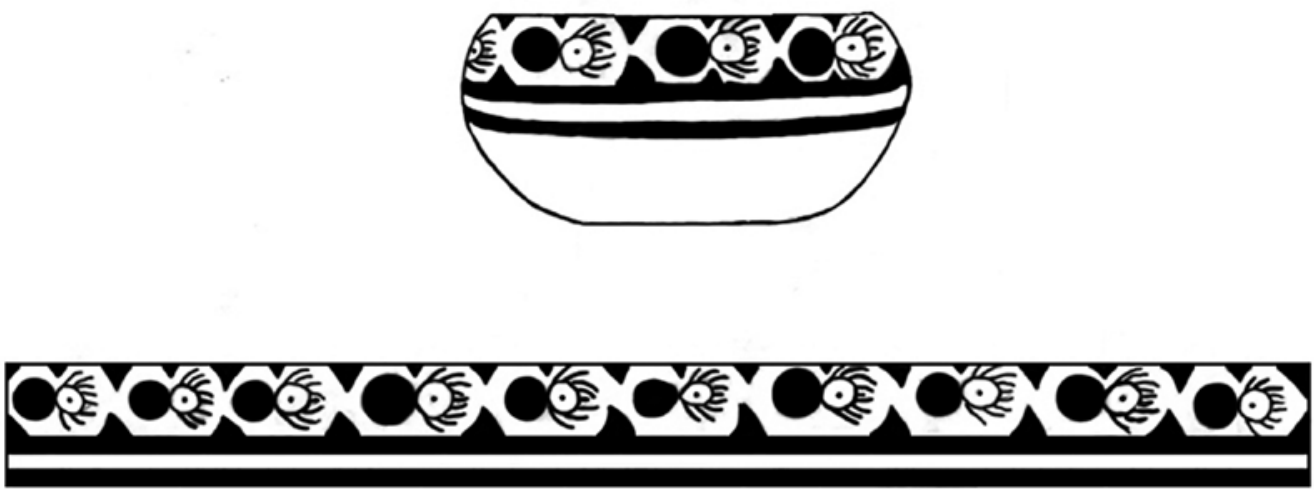

FIG. 8 B

Figura 8 B: Cuenco de mate "b". Iconografía. 


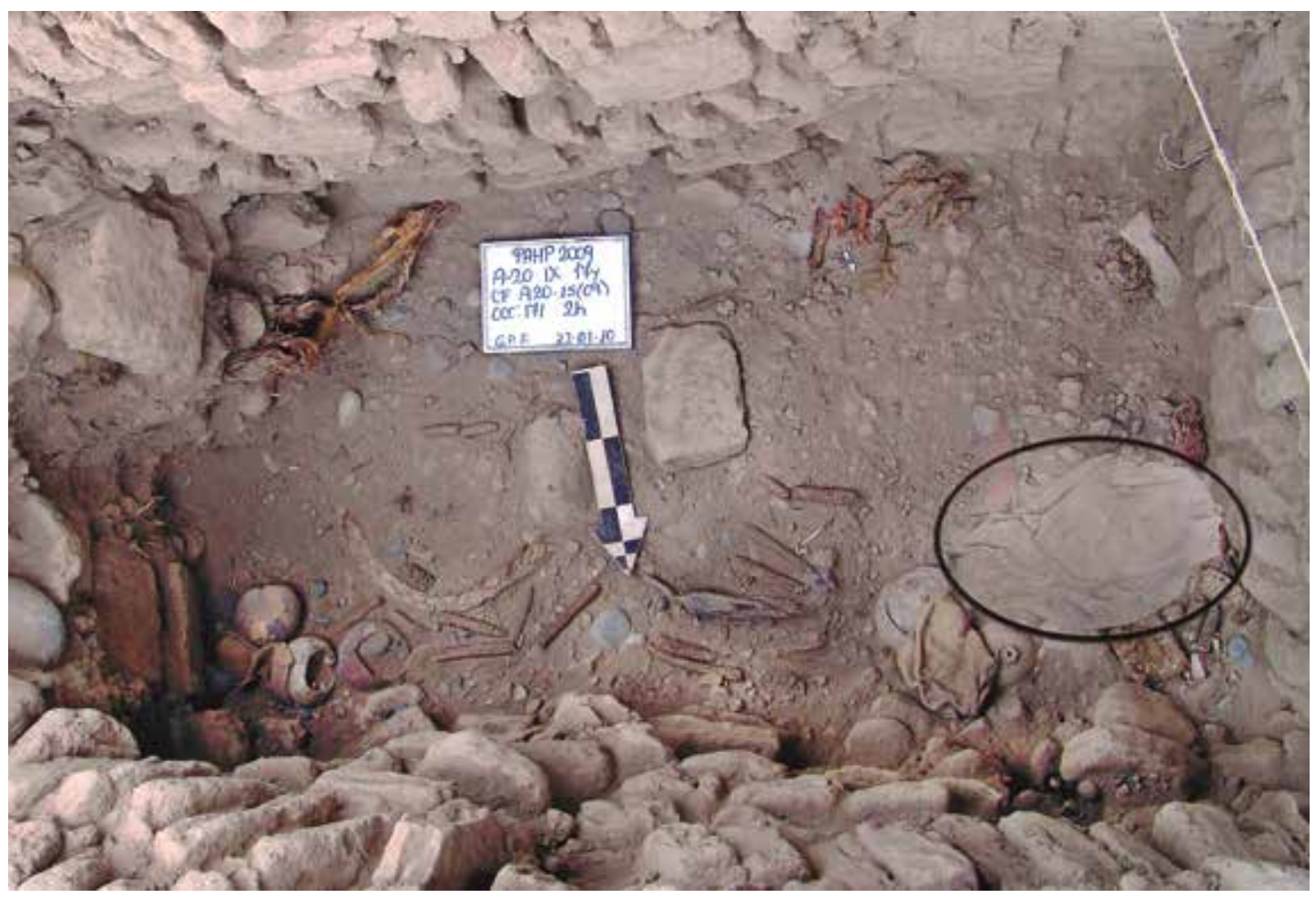

Figura 9: Contexto Funerario CF 015(09). Ubicación de la Ofrenda 2 in situ 


\begin{tabular}{|c|c|c|c|}
\hline \multirow{8}{*}{ 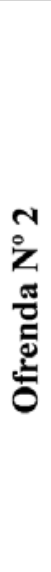 } & \multirow{6}{*}{ Nivel Superior } & \multirow{6}{*}{ Bolsa } & 4 estacas \\
\hline & & & 4 cañas \\
\hline & & & 13 husos \\
\hline & & & 4 fragmentos de agujas \\
\hline & & & 1 vestido en miniatura \\
\hline & & & $\begin{array}{l}3 \text { ovillos de hilo de } \\
\text { algodón }\end{array}$ \\
\hline & Nivel inferior & Bolsa tipo Kaywi & Semillas \\
\hline & & Plato de cerámica & Restos ictiológicos \\
\hline
\end{tabular}

Figura 10: Tabla 2. Contenido de ofrenda 2.

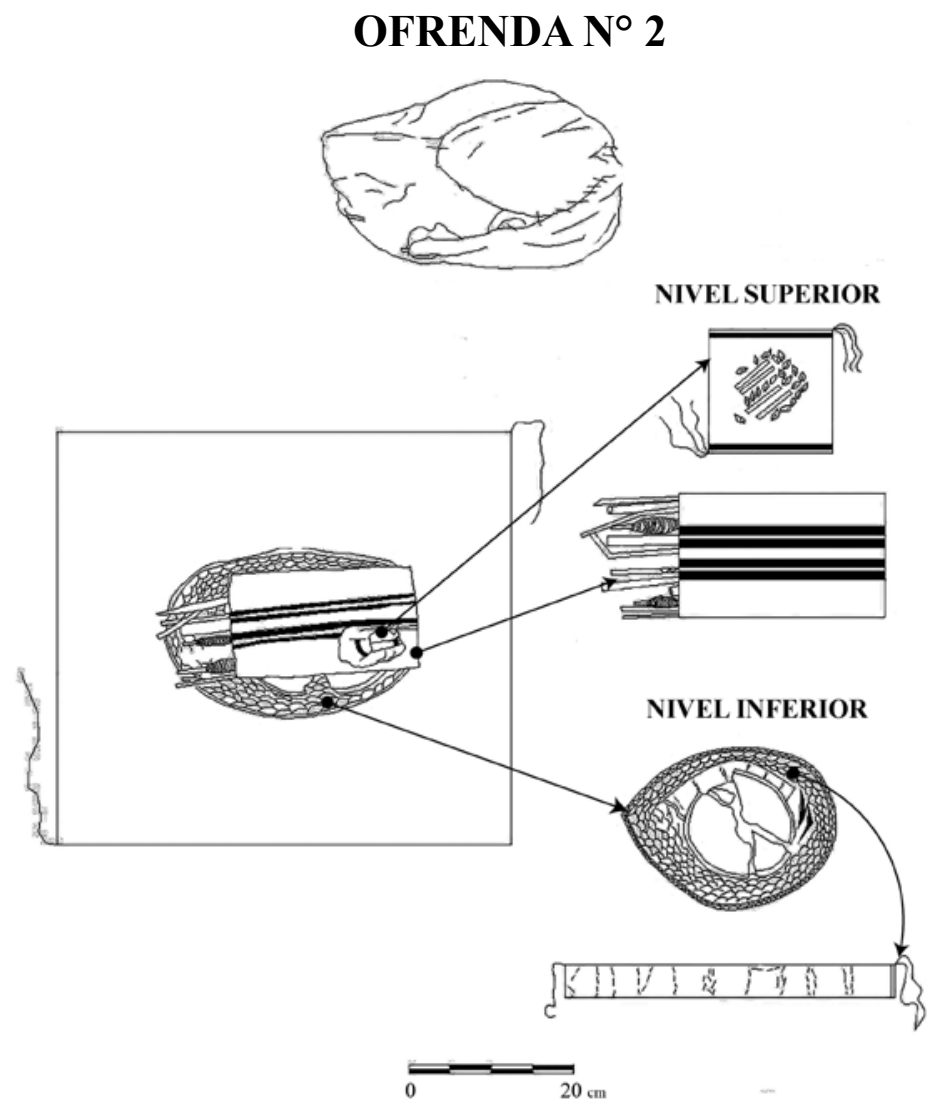


terior, presenta restos de Erythoroxylum coca y cuatro cañas de $5 \mathrm{~cm}$ de largo y $0.4 \mathrm{~cm}$ de grosor, que contienen un polvo de color gris - probablemente óxido de hierro-dispuestas en la parte central. El paño fue doblado desde sus cuatro esquinas hacia la parte central, cubriendo el contenido y atándolo por medio de un nudo simple (Figura $12 \mathrm{~A}$ )

La bolsa fue confeccionada a partir de una pieza tejida de forma rectangular, unida y cosida en los laterales, elaborada en fibra de algodón de color marrón y en técnica cara de urdimbre. Llevaba decoración listada de forma vertical de ambas caras de colores marrón oscuro, blanco y amarillo ocre de mayor grosor en la línea central. La abertura se encontraba cosida por medio de puntadas de tipo surjete, de la cual sobresalía parte de los instrumentos textiles (4 estacas de madera, 4 instrumentos en proceso de trabajo, 13 husos con hilo de algodón y 4 fragmentos de aguja). En la parte inferior de la bolsa, se halló una vestimenta femenina en miniatura y tres ovillos de hilo de algodón encontrados en la parte inferior de la bolsa (Figura 12 B).

Cuatro estacas, elaboradas en madera, que presentan grietas y huellas de uso, sobre todo en las terminaciones. Probablemente fueron introducidas en el piso con el fin de armar un telar de forma horizontal. Miden entre $21 \mathrm{~cm}$ y $23 \mathrm{~cm}$ de largo por $1 \mathrm{~cm}$ de ancho aproximadamente.

Cuatro cañas de diferentes tamaños, probablemente en proceso de trabajo para ser un instrumento dentro de la actividad textil. Tres de ellos tienen una longitud promedio de $18 \mathrm{~cm}$ y una caña de 9 $\mathrm{cm}$ y aproximadamente $0.5 \mathrm{~cm}$ de diámetro. La función específica dentro del instrumental textil aún no ha sido identificada: probablemente hayan servido como lisos o cargadores de hilo.

Trece husos, cada uno compuesto por un tallo de madera o caña de forma cilíndrica alargada. Miden entre $25 \mathrm{~cm}$ a $30 \mathrm{~cm}$ de largo y $0.5 \mathrm{~cm}$ de diámetro, aproximadamente. Se encuentran trabajados en uno de sus extremos para facilitar el hilado y cuentan con un apéndice para la inserción del piruro. Sobre la parte superior del tallo se envuelve un hilo de algodón de torsión en "Z", en fibra de un solo elemento. Cinco husos llevan hilo de color blanco, tres de color beige y cuatro de color marrón.

Cuatro fragmentos de agujas, dos de ellos se encuentran trabajados en las puntas, por lo que se infiere que fueron quebradas con el fin de introducirlas a la bolsa. Están elaboradas en madera. Miden $23.2 \mathrm{~cm}, 15.5 \mathrm{~cm}, 23.3 \mathrm{~cm}, 13.4 \mathrm{~cm}$. de longitud cada una, respectivamente, y uno $0.2 \mathrm{~cm}$ de diámetro.

Vestimenta en miniatura. Se compone de un paño de forma rectangular, doblado en los extremos y cerrado por los ejes de trama con costura de tipo surjete.

En la parte superior, se observan aberturas de forma horizontal en los extremos y parte central, las cuales forman las mangas y cuellos. El paño tiene las características formales de una vestimenta femenina. La fibra del hilo es de algodón de color mélange y está elaborado en técnica llano 1x1, con decoración en líneas verticales en la parte central del vestido de color rojo y en fibra de pelo de camélido teñido. Mide $11 \mathrm{~cm}$ largo por $9 \mathrm{~cm}$ ancho (Figura $12 \mathrm{C}$ ).

Las vestimentas representadas en miniatura aparecen anteriormente como ofrenda principal de otras tumbas de Huaca Pucllana, de similares características a las vestimentas de los personajes principales (Ccencho 2013). En Pachacamac también se registran miniaturas de unkus analizados por Ina Van Stan (1967: figura 15).

Tres ovillos de hilo de algodón, de colores marrón, marrón oscuro y beige. Miden un promedio de $5 \mathrm{~cm}$ de diámetro y fueron colocados en la parte inferior de la bolsa. En los sitios de Ancón y Huallamarca también se han encontrado este tipo de objetos textiles (Flores 2013: 53). 


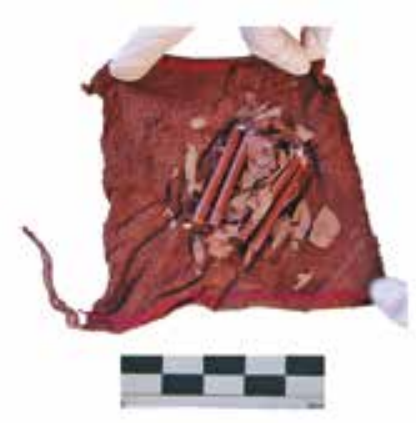

FIG. $12 \mathrm{~A}$

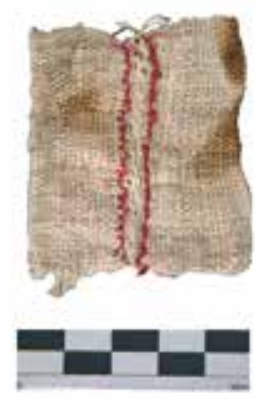

FIG. 12 C

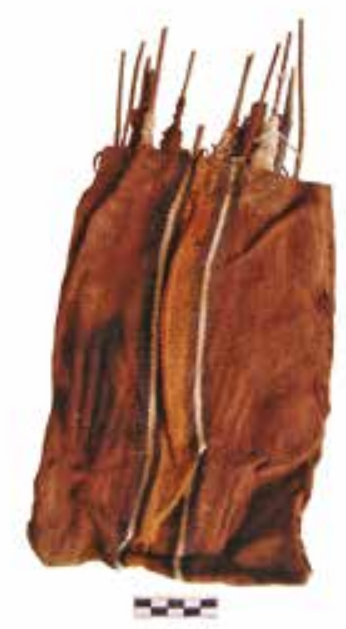

FIG. 12 B

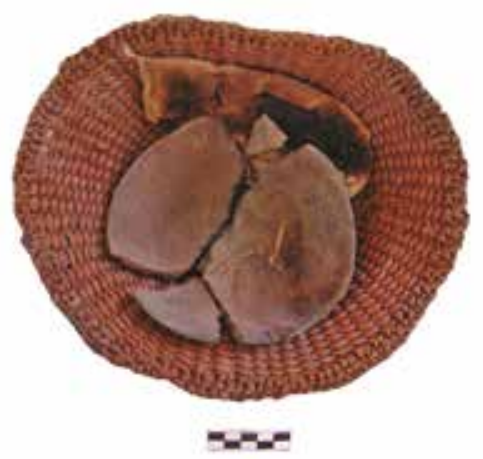

FIG. 12 D

Figura 12 A: Atado de coca y cañas; Figura 12 B: Bolsa decorada con instrumentos de textilería e hilandería; Figura 12 C: Representación de túnica en miniatura; Figura 12 D: Nivel Inferior de la ofrenda 2 


\section{NIVEL INFERIOR:}

Es el primer nivel de elementos que se colocan sobre el tejido. Se compone de una cesta de forma circular de $23 \mathrm{~cm}$ de diámetro por $5 \mathrm{~cm}$ de altura, elaborada en fibra de totora de color natural que contiene dos elementos al interior (Figura 12 D)

Un plato de cerámica de $11 \mathrm{~cm}$ de diámetro y $4 \mathrm{~cm}$ de altura, elaborado en pasta naranja Lima y de color negro debido a la cocción. El acabado es alisado y no pulimentado. Contiene vertebras y espinas de anchoveta (Engraulis ringens) en poca cantidad.

Una bolsa de forma alargada de $41 \mathrm{~cm}$ de largo por $4 \mathrm{~cm}$ de ancho, elaborada en fibra de algodón de color blanco en tejido llano 2x1, con 10 compartimentos separados por costuras de tipo hilván y surjete en hilo de algodón blanco. Al interior de cada compartimento presenta semillas en diferente número y especie (Figura 13 y 14).

\section{Resultados}

Las ofrendas descritas presentan las características formales más resaltantes de lo que comprende una ofrenda principal. La ofrenda 1 es del tipo atado y la Ofrenda 2, del tipo envoltorio. Ambas contienen diversos elementos culturales ordenados que proporcionan información del individuo ofrendado, oferentes y sobre todo, de los rituales funerarios Wari.

El orden interno de los elementos casi siempre está dividido en dos niveles: inferior y superior. Los elementos del nivel inferior sirven de soporte a los del nivel superior y pueden ser vasijas de mate, cestas de totora o platos de cerámica y nos brindan una información previa a la ideología del grupo social mediante la iconografía, el diseño y las técnicas de manufactura. En el nivel superior, en cambio, los elementos estarían indicando un tipo de oficio realizado por el personaje principal o por parte de los oferentes.

En la ofrenda 1, los contenedores de hojas de coca representan el componente principal y estarían relacionados con la actividad del sacerdocio, similares a las ofrendas encontradas en la tumba de un sacerdote, hallado en la temporada 2005. "Es probable que en la actividad del sacerdocio, dicho personaje haya empleado algunos objetos para pronosticar acontecimientos, como la coca colocada sobre paños. Además del uso de maderas denominadas paletas, los elementos de mayor distinción fueron las prendas de vestir" (Ccencho 2013: 140).

De los diseños expuestos en ambos cuencos de mate resaltan los motivos geométricos y zoomorfos: en el cuenco "a" se observan peces y aves marinas que han sido parte importante de la subsistencia de los antiguos pobladores Lima por su cercanía al litoral. Al hacer un análisis del espacio en que se relacionan estos elementos, observamos que el mar ha sido parte importante para el poblador de las comunidades costeras, sobre todo para los habitantes de Huaca Pucllana, donde las representaciones marinas se expresan en diferentes soportes culturales. Los diseños geométricos estarían representan-

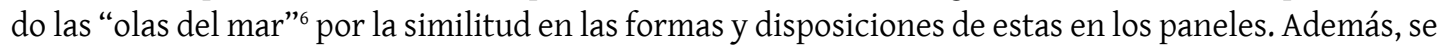
encontraron restos ictiológicos al interior del cuenco de por lo menos 2 especies marinas Sardinops sagax sagax (sardina) y Sciaena deliciosa (lorna), ambas básicas en la dieta del antiguo poblador Lima.

En la superficie del cuenco "b" es posible apreciar la representación de 8 arácnidos que en el mundo andino han sido expresados en diferentes soportes. Casi siempre han estado relacionados

6. Vargas, 2007. 


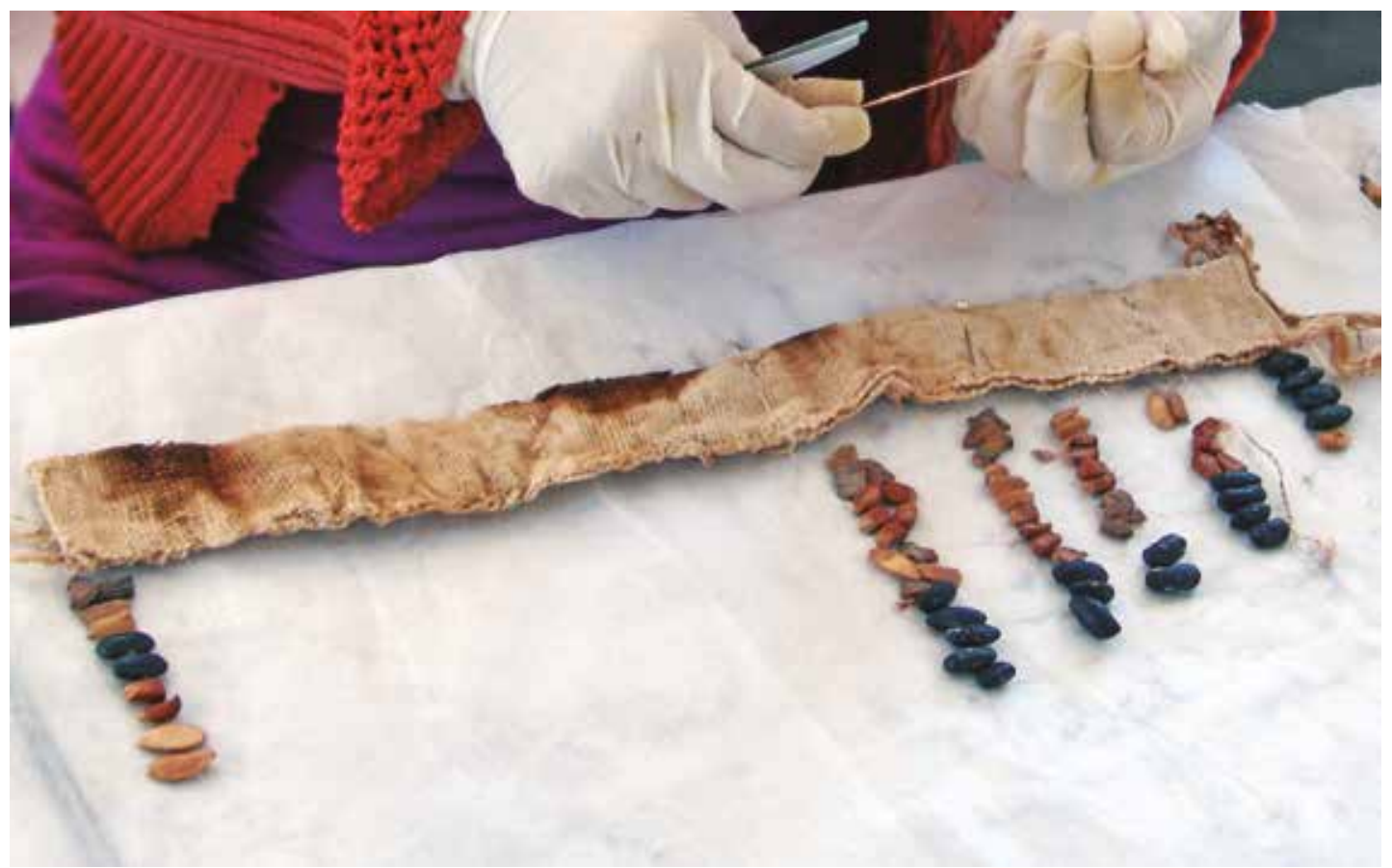

Figura 13: Bolsa de tipo kaywi.

\begin{tabular}{|c|c|c|c|c|c|c|}
\hline \multicolumn{2}{|c|}{ SECCIÓN } & \multicolumn{5}{|c|}{ ESPECIES } \\
\hline & & Fréjol & $M$ aiz & Calabaza & $M$ ate & Pacae \\
\hline Nombre & Medida & $\begin{array}{l}\text { Phaseolus } \\
\text { vulgaris sp. }\end{array}$ & $\begin{array}{l}\text { Zea mays } \\
\text { sp. }\end{array}$ & $\begin{array}{l}\text { Cucurbita } \\
\text { sp. }\end{array}$ & $\begin{array}{l}\text { Lagenaria } \\
\text { siceraria sp. }\end{array}$ & $\begin{array}{c}\text { Inga feuillei } \\
\text { sp. }\end{array}$ \\
\hline A & $4 \mathrm{~cm}$ & 5 & _ & - & - & _ \\
\hline $\mathrm{B}$ & $2.5 \mathrm{~cm}$ & 4 & 4 & 2 & - & - \\
\hline $\mathrm{C}$ & $3 \mathrm{~cm}$. & 2 & 2 & _- & 2 & 3 Fragmentos \\
\hline $\mathrm{D}$ & $3.5 \mathrm{~cm}$. & 3 & 4 & - & 2 & 6 Fragmentos \\
\hline E & $4 \mathrm{~cm}$ & 5 & 5 & 1 & 2 & 4 Fragmentos \\
\hline $\mathrm{F}$ & $2.7 \mathrm{~cm}$ & 2 & 4 & 2 & - & 1 Fragmentos \\
\hline G & $4 \mathrm{~cm}$. & 4 & 4 & 2 & 2 & - \\
\hline $\mathrm{H}$ & $4 \mathrm{~cm}$ & 4 & 1 & 2 & - & 2 Fragmentos \\
\hline I & $4.03 \mathrm{~cm}$. & 4 & 4 & 2 & 2 & 2 Fragmentos \\
\hline $\mathbf{J}$ & $3.02 \mathrm{~cm}$ & 2 & 2 & 2 & 2 & 2 Fragmentos \\
\hline
\end{tabular}

Figura 14: Tabla 3. Contenido de la bolsa tipo Kaywi. 
con la muerte, lo que se reforzaría por el tipo de contexto - mortuorio- donde fueron encontrados. Además, tal como lo señalan otros investigadores en el tema, "los cronistas mencionan la utilización de las arañas en diferentes actividades asociadas con la adivinación y sortilegio, mientras que en la sierra, cerca de Andahuaylas, la presencia y ausencia de arañas esta relacionada con las lluvias (Salazar y Burger, 1982: 239)

La ofrenda № 2 presenta una bolsa con instrumentos de hilandería y textilería, que demuestran un gran conocimiento y especialización en estas actividades. Esto puede observarse a través de la complejidad de los tejidos recuperados en otras tumbas de la misma época. En esta misma ofrenda fue hallada una representación de una vestimenta femenina en miniatura y una bolsa con compartimentos de tipo kaywi', que consiste en "bolsas con divisiones y compartimentos que contienen frijol y maíz, presentan cordones para estar colgadas en la parte externa de los fardos" (Flores 2013: 62).

Si bien los elementos que componen el nivel superior de este tipo de ofrendas nos brindan mayor información sobre los trabajos y oficios que se desarrollaban, los otros elementos que componen el ajuar funerario también nos muestran una especialización de trabajo. La mayor parte de tumbas que componen el cementerio se encuentran alteradas: solo un pequeño porcentaje del total presentan componentes intactos, por lo que el análisis osteológico de los restos óseos hallados en los niveles superficiales son importantes para identificar y descartar el número de individuos de las tumbas múltiples. El análisis osteológico realizado por la especialista Mg. Micaela Álvarez, concluyó que el CF A20 - 04 (09) estuvo representado, como mínimo, por un individuo adulto cuyo sexo no fue posible determinar debido a la ausencia de elementos diagnósticos. Sin embargo, la presencia de osteofitos marginales en la vértebra lumbar indicaba una adultez madura.

Por otro lado, el CF A20-15 (09) se trataba de una tumba múltiple, conformado por al menos seis individuos. Los restos óseos se encontraban muy incompletos y estaban representados en su mayoría por un solo hueso: un adulto y cinco subadultos. El individuo adulto (I1) presentaba una lesión propia de una infección por tuberculosis, con destrucción del cuerpo de las últimas vértebras torácicas y el consecuente colapso a nivel lumbar superior: una cifosis angular característica de esta enfermedad.

Los individuos subadultos presentan edades muy variadas: un neonato (I2), un infante de alrededor de 4 meses (I3), un infante poco mayor de 1 año (I4), un niño de aproximadamente 6 años (I5) y un niño tardío de unos 10 u 11 años (I6). Sólo en el individuo 6 pudo estimarse un sexo probablemente masculino.

\section{DisCUSIÓN DEL TEMA}

"El estudio del ajuar funerario y los demás objetos asociados con los entierros ofrece diferentes aspectos de la vida de grupos sociales desaparecidos. Se hacen inferencias acerca del estatus social de los individuos y de sus actividades; además, proporcionan información referente al carácter ritual" (Cabrera 1999: 514).

La importancia de este estudio radica en dar a conocer el aspecto religioso y social por medio de los elementos materiales asociados a los componentes de un contexto funerario. Las características particulares de este tipo de ofrendas nos proporcionan diferencias y recurrencias en las acciones que se pueden asociar con el ritual funerario, así como parte de la ideología Wari (Figura 15).

7. (Ccencho 2013: 122. Figs. 30. 31.32). 


\begin{tabular}{|c|c|c|c|}
\hline COMPONENTE & TIPO & CARÁCTER & SIGNIFICADO \\
\hline \multirow{7}{*}{ OFRENDAS } & \multicolumn{2}{|c|}{ INTERNA } & ACTIVIDAD \\
\hline & \multirow{6}{*}{ EXTERNA } & \multirow{4}{*}{ PRINCIPAL } & RITUAL \\
\hline & & & OFICIO \\
\hline & & & GÉNERO \\
\hline & & & ESTATUS \\
\hline & & \multirow{2}{*}{ SECUNDARIA } & COMIDA \\
\hline & & & BEBIDA \\
\hline
\end{tabular}

Fig. 15: Tabla 4: Tipología de las ofrendas funerarias Wari en Huaca Pucllana.

\section{RITUAL}

"A ritual is a sequence of actions. In order to reconstruct a mortuary ritual, we must invoke a logic of sequence" (Howland 1995:34). Si entendemos el ritual como una secuencia de acciones se debería analizar la lógica detrás de esta secuencia a través de la disposición de los objetos asociados dentro del ajuar funerario.

El primer ordenamiento del ritual sobre la colocación de ofrendas sería de carácter externo, basado en la ubicación de la ofrenda principal al interior de la tumba y su cercanía con los individuos enterrados. Por lo tanto, en los contextos analizados y por su recurrencia en los recuperados a lo largo del proyecto de investigación, este tipo de ofrendas estaría siempre ubicado cerca del fardo principal, mientras que las ofrendas secundarias se disponen alrededor de los fardos o en la base de la tumba y se componen de bebidas y alimentos que necesita el difunto para su viaje al más allá, como vasijas de cerámica y mate con contenido orgánico, mazorcas de maíz, huesos de camélidos y cuyes y bolsas tejidas rellenas de maíz, que pueden ser compartidas con los fardos acompañantes.

El segundo ordenamiento estaría reflejado al interior de la ofrenda, dividida en dos niveles. Se ha mencionado que cada ofrenda principal es de carácter único, sin embargo, existe una recurrencia en la disposición de los materiales. En los dos casos presentados, los soportes como cestas de junco, platos de cerámica y vasijas de mate se encontraban en el nivel inferior; mientras que los elementos con mayor información sobre el desarrollo de actividades se observaban en el nivel superior.

Los elementos empleados en el armado de la ofrenda son de carácter relevante para entender el comportamiento ritual. "Es decir, el rito funerario nos comunica algo más que una mera secuencia de actividades o un interés político, socioeconómico o adaptativo. En él, se encuentra inscrita la manera en que una sociedad concibe la muerte. Más aún, considerando que el ritual hace alusión a modelos ejemplares, podemos afirmar que el cementerio constituye la representación ideal de una sociedad" (Thomas y Salazar 1997:10).

El ritual de la colocación de ofrendas al interior de las tumbas probablemente se encontraba a cargo del sepulturero ${ }^{8}$, aunque no se descarta la posibilidad de que al tratarse de la ofrenda principal, también hayan podido participar personas con mayor cercanía al individuo, como los familiares. 


\section{Trabajo Y OFICIO}

Estudios anteriores relacionados al tema han podido clasificar e identificar una diferenciación de actividades en relación al género del individuo a través de las características de sus ofrendas.

"Con respecto a los oficios definidos para la época Horizonte Medio 2 b -3 se exponen herramientas de mayor importancia para la persona enterrada, mostrando que la textilería estaba casi exclusivamente a cargo de las mujeres, mientras que la pesca era ocupación masculina" (Kaulicke 1997b: 65). Contrariamente a esto, los objetos asociados internos recuperados en las excavaciones del cementerio Wari del sitio Catalina Huanca demostraron que los instrumentos textiles estaban relacionados tanto con hombres como con mujeres (Álvarez 2011: 31). Asimismo, se han encontrado anteriormente bolsas de tipo kaywi en el cementerio Wari de Huaca Pucllana ${ }^{9}$, aunque en este caso fueron halladas dentro de la ofrenda y no como parte de la indumentaria del fardo principal. Esta bolsa en particular tenía diez compartimentos, con diferentes tipos y números de semillas que corresponden a frejol, maíz, calabaza, mate y pacae. Todos estos elementos son recurrentes dentro de las ofrendas funerarias Wari y muestran parte de su dieta y sus actividades agrícolas.

\section{ESTATUS SOCIOPOLÍTICo}

La mayor parte de las tumbas de este cementerio son múltiples: en ellas se puede hacer una clasificación de los fardos según su jerarquía. Existe un fardo principal, que es colocado en el lado sur de la tumba, con la mirada al Norte o al Este. A su lado, se encuentran uno o más fardos de acompañantes, según la importancia del individuo principal, y alrededor de ellos, se disponen las ofrendas secundarias y principales. (Flores, 2013:41).

Este tipo de jerarquización también se repite en el sitio de Ancón, donde fueron diferenciados los individuos principales, dispuestos sobre el piso y orientados hacia el norte. Los fardos llevaban cabezas postizas y adornos de metal que indican una especial posición social (Kaulicke 1997: 69).

Conocer la jerarquía sociopolítica del individuo enterrado a través del ajuar funerario ha sido de gran interés para otros investigadores. "El uso de los tejidos como símbolo de prestigio y status socioeconómico aparece registrado en los contextos funerarios. Telas suntuosas se encuentran en tumbas ricas en ofrendas, mientras que telas menos finas aparecen asociadas a tumbas pobres" (Fung 2004: 250).

En las crónicas observamos que la hoja de coca casi siempre aparece como un bien de lujo de carácter ritual o medicinal. Las características formales de las hojas de coca encontradas en la Ofrenda 1 difieren de las hojas de coca actuales en la sierra: las primeras son de tamaño pequeño y alargado, por lo que se infiere que se trata de una hoja de coca costeña, a la que Rostworowski denominaba Tupa coca. ${ }^{10}$

Esta diferenciación del contenido de las ofrendas principales nos enseña las variaciones en las posiciones sociales de los individuos enterrados, asumiendo las reglas funerarias orientadas a tres categorías: sexo, edad y riqueza (Kaulicke 1997a:27). Estos tres factores se aprecian en mayor o menor medida en el tratamiento de los objetos asociados.

8. Persona encargada de preparar los fardos (Flores, 2013).

9. Ajuar funerario de la tumba del Gran Sacerdote (Flores, Ccencho: 2013).

10. Tomado de Castro de la Mata, 1997:59. 


\section{A Manera de Conclusión}

Se puede decir que a lo largo de las investigaciones realizadas sobre el tema, han logrado definirse los componentes que conforman un contexto funerario Wari para la Costa Central. De todos ellos, las ofrendas nos ofrecen mayor información del individuo enterrado así como de la sociedad comprometida.

Existen varios tipos de ofrendas dentro del ajuar funerario. Primero, están las ofrendas al interior del fardo, relacionadas al oficio o actividad ligada a la persona, así como a su jerarquía. Las ofrendas externas, por otro lado, se pueden clasificar en dos grupos: están las ofrendas principales, que cumplen un objetivo importante dentro de la tumba Wari y son ofrendas personalizadas, armadas y preparadas especialmente para el individuo principal, dispuestas al frente o al costado de este, y contienen diversos elementos ordenados que responden a un mayor significado del ritual funerario. En cambio, las ofrendas secundarias, compartidas entre el individuo principal y los acompañantes, están mayormente relacionadas con la bebida, la comida y a esta idea generalizada sobre el pasaje a la muerte del mundo andino.

Respecto a la iconografía representada de insectos, aves y especies marinas en los soportes, esta nos expone la relación que tenía el hombre de la época con el mar y parte de su ideología.

Por otro lado, los instrumentos textiles ofrendados en conjunto demuestran la fuerte producción textil que se practicaba en la época y su grado de especialización. Algunos de estos instrumentos presentan huellas de desgaste, es decir, no fueron hechos con el propósito de ser ofrenda en un principio, por lo que se infiere que podrían haber sido de uso personal del individuo principal o de los oferentes. La presencia de hojas de coca se relaciona con la adivinación o sacerdocio y los restos ictiológicos también demuestran la práctica de la pesca.

Finalmente, es importante señalar que la importancia de reconocer este tipo de ofrendas funerarias nos muestra la relación entre el individuo y los otros participantes relacionados a esta práctica funeraria. El gran objetivo de este estudio de ofrendas es tratar de acercarnos a descifrar el concepto de la muerte para los Wari, el cual debe de estar relacionado con su política de Estado y sus tradiciones locales.

\section{Agradecimientos:}

En primer lugar, agradecer a la Dra. Isabel Flores Espinoza por darme la autorización para acceder a los registros de excavación y gabinete de la temporada 2009-2010 del PICPVHP, al equipo del Proyecto Arqueológico Huaca Pucllana por el apoyo en los análisis, los registros gráficos y fotográficos, a la Lic. Hilda Chuchón por sus aportes en la metodología e intervención, al igual que a la Lic. Sara Vargas. Al biólogo Giancarlo Ubillus por la identificación del material botánico y a la Mg. Micaela Álvarez por el análisis de los restos osteológicos. Finalmente a los colegas y amigos por los comentarios y críticas constructivas de este trabajo que me permite finalmente contribuir al conocimiento de los Wari en la Costa Central.

\section{BibliografíA}

\section{ÁLVAREZ, Micaela}

2011 Contextos funerarios del Horizonte Medio en el Montículo 6 de Catalina Huanca. Una aproximación biológica y arqueológica. Tesis para optar el título de Máster en Antropología Física: Biodiversidad y Evolución Humana en la Universidad Autónoma de Madrid. Universidad Complutense. Universidad de Alcalá de Henares. España. 
CORNEJO, Miguel

2007 Informe Final del Proyecto de Evaluación Arqueológica Catalina Huanca. Lima. Presentado al Instituto Nacional de Cultura.

2009 Informe Final del Proyecto de Rescate Arqueológico Catalina Huanca. Lima. Presentado al Instituto Nacional de Cultura.

BELMONTE Eliana, ORTEGA Marietta, ARÉVALO Patricia, CASMAN Vicki, CARTMELL Larry

2001 "Presencia de la Hoja de Coca en el Ajuar Funerario de tres cementerios del periodo Tiawanaku: AZ-140, AZ 6 y PLM 3". Chungará - Revista de Antropología Chilena. Volumen 33 № 1. Arica, pp. 125-135.

CABRERA, Rubén

1999 "Las prácticas funerarias de los antiguos teotihuacanos" En: Prácticas Funerarias en la Ciudad de los Dioses. Cap. XVI Editado por Instituto de Investigaciones Antropológicas y la Dirección General de Asuntos del Personal Académico de la Universidad Nacional Autónoma de México. D.F. - México.

CÁRDENAS, Mercedes y HUDTWALCKER, M.

1997 “Practicas Funerarias en Puerto Supe, Dpto. Lima, Durante el Horizonte Medio”. Boletín de Arqueología PUCP. $\mathrm{N}^{\circ}$ 1. Lima, pp. 233-240.

CASTRO DE LA MATA, Ramiro

1977 “La coca en la obra de Guamán Poma”. En: Boletín del Instituto Riva Agüero. № 11, Lima, pp. $57-79$

CCENCHO, José

2013 “Excavación de la tumba del Sacerdote": Los Wari en Pucllana, la tumba de un sacerdote. Ministerio de Cultura. Lima, pp. 84-141.

FLORES, Isabel

1981 “Investigaciones Arqueológicas en Huaca Juliana, Miraflores”. En: Boletín de Lima. № 13. Lima, pp. 65-70.

2005 Pucllana: Esplendor de la Cultura Lima. Instituto Nacional de Cultura. Lima.

2010 Informe final de las actividades realizadas por el Proyecto de Investigación, Conservación y puesta en valor Huaca Pucllana 2009 presentado al Ministerio de Cultura, Lima.

2013 Los Wari en Pucllana, la tumba de un sacerdote. Ministerio de Cultura. Lima.

FLORES, Isabel; CHUCHON, Hilda; CCENCHO, José; VARGAS, Pedro

2012 La doble tela de los muertos, tejidos especiales Wari de Pucllana. Auqui ediciones. Proyecto de Investigación, Conservación y Puesta en Valor Huaca Pucllana. Lima, 128 pp.

FRAME, Mary

2004 "Un fardo funerario del Horizonte Tardío del sitio Rinconada Alta, Valle del Rímac". En: Arqueología de la Costa Central del Perú en los periodos tardíos. Boletín de Instituto Francés de Estudios Andinos, tomo 33, $\mathrm{N}^{\circ}$ 3. Lima, pp. 
FUNG, Rosa

2004 “La documentación en la conservación textil". En: Quehaceres de la Arqueología Peruana. Compilación de escritos. Museo de Arqueología y Antropología, Centro Cultural de la UNMSM. Lima, pp. 245-275.

GARCÍA, LUIS

2013 “Milenarios fardos waris son hallados en Huaca Pucllana”. El Comercio. Lima-Perú.

HOWLAND, John

1995 "Behavior and belief in Ancient Peruvian Mortuory Practice". Tom Dillehay (e.d.). Tombs for living: Andean mortuary practices. A Symposium at Dumbarton Oaks 12th and 13 th October 1991. Washington D.C., pp. 27-42.

HORKHEIMER, Hans

2004 Alimentación y obtención de alimentos en el Perú prehispánico. 2da edición al castellano. Instituto Nacional de Cultura. Lima.

HUERTAS, Lorenzo

1981 La Religión en una sociedad rural andina del siglo XVII. Lima.

ISBELL, William $\mathrm{H}$.

1985 “El origen del Estado en el valle de Ayacucho". Revista Andina. № 1. Año 3. Publicación Semestral del Centro "Bartolomé de las Casas". Cusco, Perú. pp. 57-106.

2003 “Sin Mallkis que adorar: los muertos Huari”. Arqueológicas. Revista del Museo Nacional de Arqueología, Antropología e Historia del Perú. Vol. 26. Lima.

KAULICKE, Peter

1997a “La muerte en el Antiguo Perú. Contextos y conceptos funerarios: una introducción”. Boletín de Arqueología PUCP, $\mathrm{N}^{\mathrm{O}}$ 1. Lima, pp.7-54.

1997b Contextos Funerarios de Ancón. Esbozo de una síntesis analítica. PUCP Primera edición. Lima.

2000 Memoria y Muerte en el Perú Antiguo. PUCP. Primera edición. Lima.

2000 La sombra de Pachacamac: Huari en la Costa Central. Boletín de Arqueología PUCP N 4. Lima, Perú, pp. 313-358.

2001 "Vivir con los ancestros en el Antiguo Perú". La memoria de los ancestros. Luis Millones y Wilfredo Kapsoli, Compiladores. Universidad Ricardo Palma. Lima, pp. 25-61.

LUMBRERAS, Luis

1980 “El Imperio Wari”. Historia del Perú, Tomo II, Juan Mejía Baca, editor. Lima., pp. 11-91.

MILLONES, Luis

2005 “La Muerte como Espectáculo”. Millones, Luis \&Takahiro Kato (Eds.). Desde el exterior. El Perú y sus estudiosos. Tercer Congreso Internacional de Peruanistas. Nagoya, Lima: Fondo Editorial de la Facultad de Ciencias Sociales, Universidad Nacional Mayor de San Marcos. 
MOGROVEJO, Juan y Segura, Rafael.

2000 "Horizonte Medio en el Conjunto Arquitectónico Julio C. Tello de Cajamarquilla". Boletín de Arqueología PUCP. N 4. Lima, pp. 565-582. Pontificia Universidad Católica del Perú.

POZZI-ESCOT, Denise y ÁNGELES, Rommel

2005 “Un Fardo Funerario en Huaca Malena, valle de Asia”. Corriente arqueológica, muerte y evidencias funerarias en los Andes centrales: avances y perspectivas. Lima, pp. 119-148.

QUIJADA, Sergio

1982 La coca en las costumbres indígenas. Apuntes del folclore. Imprenta Ríos. Huancayo, 82 pp.

RAVINES, Rogger

1977 “Prácticas Funerarias en Ancón (primera parte)". Revista del Museo Nacional. № 43. INC. Lima, pp. 327-397.

1981 “Prácticas Funerarias en Ancón (segunda parte)". En: Revista del Museo Nacional Lima N 45 INC T.XLV 1981. pp: 89-166. Lima, pp. 255-288.

ROSTWOROWSKI, María

2004 "Plantaciones prehispánicas de Coca en la Vertiente del Pacífico" Costa Peruana Prehispánica. Instituto de Estudios Peruanos. Lima.

SALAZAR - BURGUER, Lucy y BURGUER, Richard

1982 "La araña en la iconografía del Horizonte Temprano". Beitrage zur Allgemeinen und Vergleichenden Archaologie. $N^{0}$ 4. Mainz am Rhein, pp. 213-253.

SEGURA, Rafael

1997 “Contextos Funerarios a fines del Horizonte Medio en la Necrópolis de Ancón, perspectivas de análisis e investigación". Boletín de Arqueología PUCP. Vol. 1. Pontificia Universidad Católica del Perú, Lima, pp. 241-251.

SHADY, Ruth

1988 “La época Wari como interacción de las sociedades regionales”. En: Revista Andina. № 1. Cusco, pp. $67-132$

TELLO, Julio C.

1999 “Arqueología del Valle de Lima”. Cuadernos de Investigación del Archivo Tello. № 1. Museo de Arqueología y Antropología, Universidad Nacional Mayor de San Marcos. Lima.

THOMAS WINTER, Carlos y SALAZAR, Diego

1997 "Perspectivas teóricas para una arqueología interpretativa de la muerte". Anales Universidad de Chile № 6 [en línea] http://www.anales.uchile.cl/index.php/ANUC/article/viewFile/3133/3048 [Consulta: 16-05-2014].

TRIVELLI, Carlo.

2008 "Hallan una tumba intacta Wari en Huaca Pucllana”. El Comercio. Perú. 
VARGAS, Pedro

2007 "El tiburón y las olas: Apuntes preliminares para un entendimiento de las figuras arqueológicas Lima de Huaca Pucllana (500 - 700 d. C)”. Cuadernos de investigación. Instituto Nacional de Cultura. $\mathrm{N}^{\circ} 01$ Lima.

VILLACORTA, L. y Tosso Walter.

2000 “El estilo Teatino: Nuevas perspectivas". Arqueológicas N 24. Museo Nacional de Arqueología, Antropología e Historia. Lima, 79-127.

CHACALTANA, Sofia y NASH, Donna

2009 "Análisis de las ofrendas en los Andes Sur Centrales. Las ofrendas como tradición de origen prehispánico: El caso de Cerro Baul, Valle alto de Moquegua”. Andes $\mathrm{N}^{\circ}$ 7. Arqueología del área centro sur andina. Lima, pp. 155-180. 